\title{
CLIMATOLOGIA DE FRENTES FRIAS NO LITORAL DE SANTA CATARINA
}

\author{
Maria Laura Guimarães Rodrigues ${ }^{1}$, Davide Franco² e Shigetoshi Sugahara ${ }^{3}$ \\ Recebido em 28 maio, 2004 / Aceito em 1 setembro, 2004 \\ Received May 28, 2004 / Accepted September 1, 2004
}

\begin{abstract}
A climatology of cold fronts at the coast of State do Santa Catarina, Brazil, is established based on 10-year period (1990-1999) of NCEP-NCAR reanalysis data. The cold front passages were objectively identified taking into account the wind shifts to a southerly direction, as well as the persistence of southerly wind for at least one day, and a decreasing of air temperature. The results show that, on the average, 3 to 4 cold fronts reach coast of Santa Catarina, each month, with an interval of 8 days. The composite data analysis, using the date of days of cold front passages at Santa Catarina as reference, shows clearly a climatological pattern of evolution, with cold front moving typically from southwest to northeast. In terms of seasonal mean, during winter, one day before reaching coast of Santa Catarina (day -1 ) the cold front is observed at Rio Grande do Sul. After passing at Santa Catarina (day 0), it continues to move equatorward, reaching the coast of Rio de Janeiro one day later $($ day +1$)$, until it reaches latitudes close to $20^{\circ} \mathrm{S}($ day +2$)$, in the its stage of dissipation. In the third day, after the passage at Santa Catarina, the cold front is no more observed. Similar pattern of evolution is observed during summer, though the cold fronts are less intense and of slightly more rapid dissipation.
\end{abstract}

Keywords: climatology of cold fronts, movement of cold fronts, cold fronts at the coast of Santa Catarina, Brazil.

RESUMO. Uma climatologia de frentes frias é estabelecida para o litoral do Estado de Santa Catarina, com base nos dados de reanálises do NCEP-NCAR, do período de 10 anos, de 1990 a 1999. As passagens de frentes frias foram objetivamente identificadas levando em conta o giro do vento para direção sul, persistência do vento de sul por pelo menos um dia, e uma queda de temperatura do ar simultânea ao giro do vento ou até dois dias depois. Os resultados mostram que, na média, de 3 a 4 frentes frias atingem a costa de Santa Catarina, mensalmente, com um intervalo de 8 dias. As análises da composição de dados, usando como referência os dias de passagens de frentes frias em Santa Catarina, mostram claramente um padrão climatológico de evolução com frente fria movendo-se tipicamente de sudoeste para nordeste. Em termos das médias sazonais, durante o inverno, um dia antes da passagem em Santa Catarina (dia -1), a frente fria é observada no Rio Grande do Sul, e depois de passar por Santa Catarina (dia 0), continua avançando para latitudes mais baixas, alcançando o litoral do Rio de Janeiro um dia depois (dia +1 ), até atingir posteriormente latitude de aproximadamente $20^{\circ} \mathrm{S}($ dia +2 ), já em fase de dissipação. № terceiro dia após a passagem por Santa Catarina, ela não é mais identificada. Padrão climatológico de evolução semelhante é observado no verão, embora nessa época as frentes frias tenham menor intensidade e dissipação ligeiramente mais rápida.

Palavras-chave: climatologia das frentes frias, movimento das frentes frias, frentes frias no litoral de Santa Catarina.

\footnotetext{
${ }^{1}$ Centro Integrado de Meteorologia e Recursos Hídricos de Santa Catarina, Secretaria de Estado do Desenvolvimento Rural e da Agricultura, Rod. Admar Gonzaga 1347, Itacorubi, Caixa Postal 502, CEP: 88034-901 Florianópolis - SC. Tel: (48) 239-8064/8066/8067; Fax: (48) 239-8065 - E-mail: laura@sol.climerh.rct-sc.br ${ }^{2}$ Departamento de Engenharia Ambiental, Laboratório de Hidráulica Marítima, Universidade Federal de Santa Catarina, Caixa Postal 5039, CEP: 88040-970 Florianópolis - SC. Tel: (48) 331-9992; Fax: (48) 331-9823/9252 - E-mail: franco@ens.ufsc.br

3 Instituto de Pesquisas Meteorológicas e Faculdade de Ciências, Universidade Estadual Paulista, Campus Bauru, Av. Luiz Edmundo C. Coube s/n, Vargem Limpa, Caixa Postal 281, CEP: 17001-970 Bauru - SP. Tel: (14) 3103-6030, ramal 143; Fax: (14) 3203-3649 - E-mail: shige@ipmet.unesp.br
} 


\section{INTRODUÇÃO}

As mudanças nas condições meteorológicas observadas nas regiões Sul e Sudeste do Brasil estão geralmente associadas à passagem, formação ou intensificação de frentes frias, sistemas meteorológicos típicos de latitudes médias e atuantes no litoral brasileiro em todas as épocas do ano (Kousky, 1979 e Satyamurty et al., 1998).

Associados aos distúrbios de grande-escala, os sistemas frontais deslocam-se acompanhados de ciclones e anticiclones móveis, alterando os campos de pressão atmosférica, de vento, e de outras variáveis atmosféricas, ao longo da sua trajetória (Wallace \& Hobbs, 1977). Na plataforma sul-sudeste do Brasil, esses distúrbios atmosféricos podem provocar sobre-elevações do nível do mar (Stech \& Lorenzzetti, 1992; Camargo \& Harari, 1994; Castro e Lee, 1995, Innocentini \& Caetano Neto, 1996; Rocha et al. 2004).

Alterações significativas das correntes e das marés, por sua vez, podem afetar atividades marítimas, de pesca e navegação, dificultando operações em embarcações, portos e plataformas. Elevações extremas do nível do mar podem resultar em problemas de erosão costeira, favorecendo a destruição da orla e intrusões salinas.

Nos últimos anos, os setores petroleiro, portuário e pesqueiro estabeleceram, em Santa Catarina, convênios e parcerias com instituições como 0 LaHiMar/UFSC (Laboratório de Hidráulica Marítima/Universidade Federal de Santa Catarina) e o Climerh/Epagri (Centro Integrado de Meteorologia e Recursos Hídricos/Empresa de Pesquisa Agropecuária e Extensão Rural), para o desenvolvimento de estudos e serviços que permitissem um melhor conhecimento das condições atmosféricas e marítimas no litoral de Santa Catarina.

Na plataforma catarinense, Truccolo \& Franco (2000) identificaram uma resposta do nível do mar altamente influenciada por passagens frontais, mas ainda são poucos os trabalhos a respeito de frentes frias sobre a região ou mesmo de sua climatologia, direcionados para esta região do litoral brasileiro. Assim, este estudo tem como principal objetivo definir uma climatologia sinótica de frentes frias no litoral de Santa Catarina, examinando estatisticamente as frentes frias que passaram por essa região durante 10 anos, de 1990 a 1999. A técnica estatística usada é basicamente de composição de dados (ver, por exemplo, Rocha et al., 2004).

\section{REGIÃO DE ESTUDO}

0 Estado de Santa Catarina está localizado na região Sul do Brasil (Fig. 1). Ao longo dos 561,4 km de extensão do seu litoral, en- tre as latitudes de $25^{\circ} 57^{\prime} 41^{\prime \prime} \mathrm{S}$ e $29^{\circ} 23^{\prime} 55^{\prime \prime} \mathrm{S}$, desenvolvem-se importantes atividades do setor marítimo, entre elas a pesca artesanal, em diferentes níveis de organização, e a pesca industrial. 0 Estado destaca-se como um dos maiores na produção pesqueira nacional, e o pólo pesqueiro industrial, localizado em Itajaí, é 0 maior do Brasil.

Próximo à ilha de São Francisco do Sul, está localizada uma monobóia de operações da Petrobrás S.A., onde naviostanque descarregam petróleo bruto. Entre os portos em atividade, destaca-se 0 Porto de Itajá, operando carga de contâiners, de alto valor agregado, e contribuindo com $65 \%$ da receita cambial do Estado. Além deste, outros dois portos estão localizados em Santa Catarina, nos municípios de São Francisco do Sul e de Imbituba.

\section{FRENTES FRIAS NA AMÉRICA DO SUL}

Na América do Sul, Satyamurty \& Mattos (1989) identificaram a região centro-sul do continente, localizada entre os dois anticiclones subtropicais, do Pacífico e Atlântico Sul, como altamente frontogenética (favorável à formação e intensificação de frentes). 0 desenvolvimento da zona frontal é verificado em associação aos distúrbios baroclínicos provenientes do Pacífico, que atravessam os Andes em latitudes médias.

As frentes frias que percorrem o litoral da América do Sul são, tipicamente, configuradas na direção noroeste-sudeste e apresentam uma trajetória de sudoeste para nordeste. Para ilustrar isto, um exemplo de passagem frontal, observada entre os dias $9 \mathrm{e}$ 10 de agosto de 1996, na região sul do Brasil, é apresentada na Fig. 2. Os campos de pressão ao nível do mar, de vento a 10 metros de altura, e de temperatura em $1000 \mathrm{hPa}$ são de reanálises do National Centers for Environmental Prediction - National Center for Atmospheric Research dos Estados Unidos da América do Norte (NCEP-NCAR).

No dia 9 , a frente fria é observada desde o Paraguai até 0 Rio Grande do Sul, na linha que separa dois fluxos distintos, associados a massas de ar de diferentes características (Fig. 2a). Ventos de quadrante norte são observados em Santa Catarina, onde predomina a alta subtropical do Atlântico Sul. Na retaguarda do sistema frontal, a penetração do anticiclone polar favorece um fluxo de sul no setor norte da Argentina e Uruguai. 0 ciclone associado ao sistema frontal é observado no litoral do extremo sul do Brasil (centro em $34^{\circ} \mathrm{S}$ e $53^{\circ} \mathrm{W}$ ). Verifica-se ainda, o predomínio de ventos fortes, na região do pós-frontal, ao sul da linha da frente.

Na Fig. 2b, do campo de temperatura, no dia 9, a linha frontal separa a região de altas temperaturas, associadas à massa de ar 


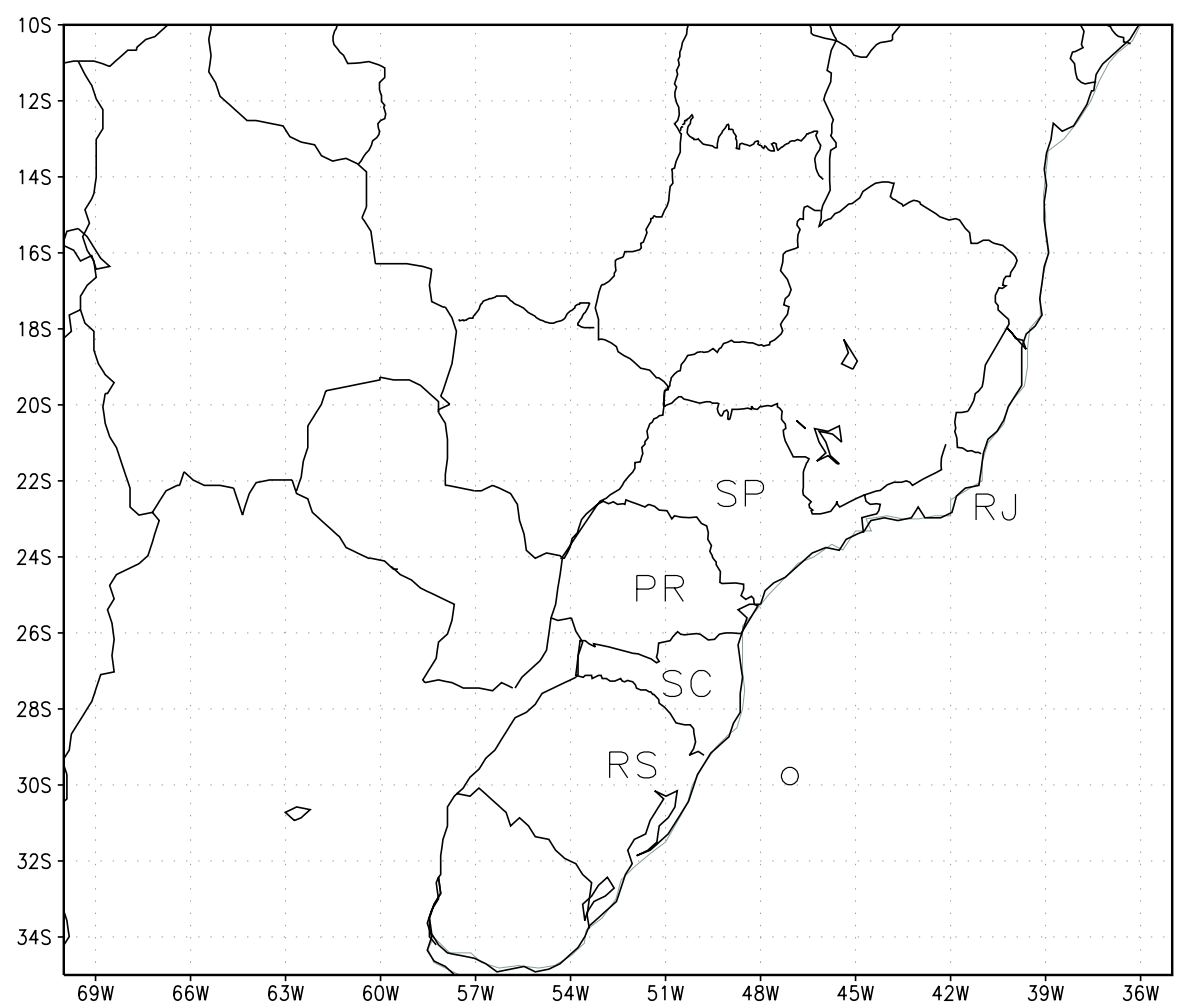

Figura 1 - A região em estudo. 0 Estado de Santa Catarina é indicado por SC. A figura exibe também outros Estados referidos neste trabalho: Rio Grande do Sul (RS), Paraná (PR), São Paulo (SP) e Rio de Janeiro (RJ). 0 ponto no Oceano Atlântico $\left(30^{\circ} \mathrm{S}\right.$ e $\left.47.5^{\circ} \mathrm{W}\right)$, marcado por círculo aberto, foi usado para identificação de passagens de frentes frias.

Figure 1 - The region of study. The State of Santa Catarina is indicated by SC. The figure also displays other States referred in this work: Rio Grande do SuI (RS), Paraná (PR), São Paulo (SP) and Rio de Janeiro (RJ). The point at the Atlantic Ocean $\left(30^{\circ} \mathrm{S}\right.$ e $\left.47.5^{\circ} \mathrm{W}\right)$, marked by open circle, was used for identification of the cold fronts passages.

quente de origem subtropical, e a região da zona frontal, de forte contraste térmico. Associada à penetração do anticiclone polar, a massa de ar frio de origem polar provoca baixas temperaturas em todo 0 norte da Argentina.

No dia 10, a frente fria desloca-se em direção às altas temperaturas, sendo observada desde o setor norte do Estado de São Paulo, estendendo-se ao longo do cavado, em direção ao oceano Atlântico Sul, enquanto o ciclone associado move-se em direção às altas latitudes (Fig. 2C). Em Santa Catarina, a virada do vento para 0 quadrante sul caracteriza a passagem frontal no Estado e, na retaguarda da frente fria, 0 anticiclone polar torna-se predominante no sul do Brasil, Uruguai e norte da Argentina.

Um forte gradiente de temperatura, no dia 10 (Fig. 2d), é observado nos Estados de Santa Catarina, Paraná e Mato Grosso do Sul, na região ao sul da linha da frente, e o centro da massa polar, na região central da Argentina.

As frentes frias que percorrem o litoral sul-americano, em ge- ral, atingem latitudes em torno de $20^{\circ} \mathrm{S}$, onde tem início seu processo de dissipação, conhecido como frontólise (Oliveira, 1986; Satyamurty \& Mattos, 1989; Cavalcanti \& Kousky, 1996).

Ao atingirem o Atlântico Sul, os centros de baixa pressão que acompanham as frentes apresentam uma tendência de movimento na direção leste-sudeste. 0 centro dos anticiclones, depois de cruzar os Andes, adquire um componente para nordeste, na retaguarda das frentes, antes de deslocar-se para o litoral da América do Sul e integrar-se à alta subtropical do Atlântico Sul (Taljaard, 1967 e Satyamurty et al., 1998).

Segundo Oliveira (1986), as frentes frias que ultrapassam latitude de em torno de $35^{\circ} \mathrm{S}$ podem adquirir uma trajetória mais meridional, em direção ao Equador, mas os sistemas que atravessam a costa leste da América do Sul em latitudes ao sul de $40^{\circ} \mathrm{S}$, apresentam uma trajetória predominantemente zonal.

0 número de frentes frias diminui na medida em que avança em direção às latitudes baixas e o número máximo ocorre no lito- 


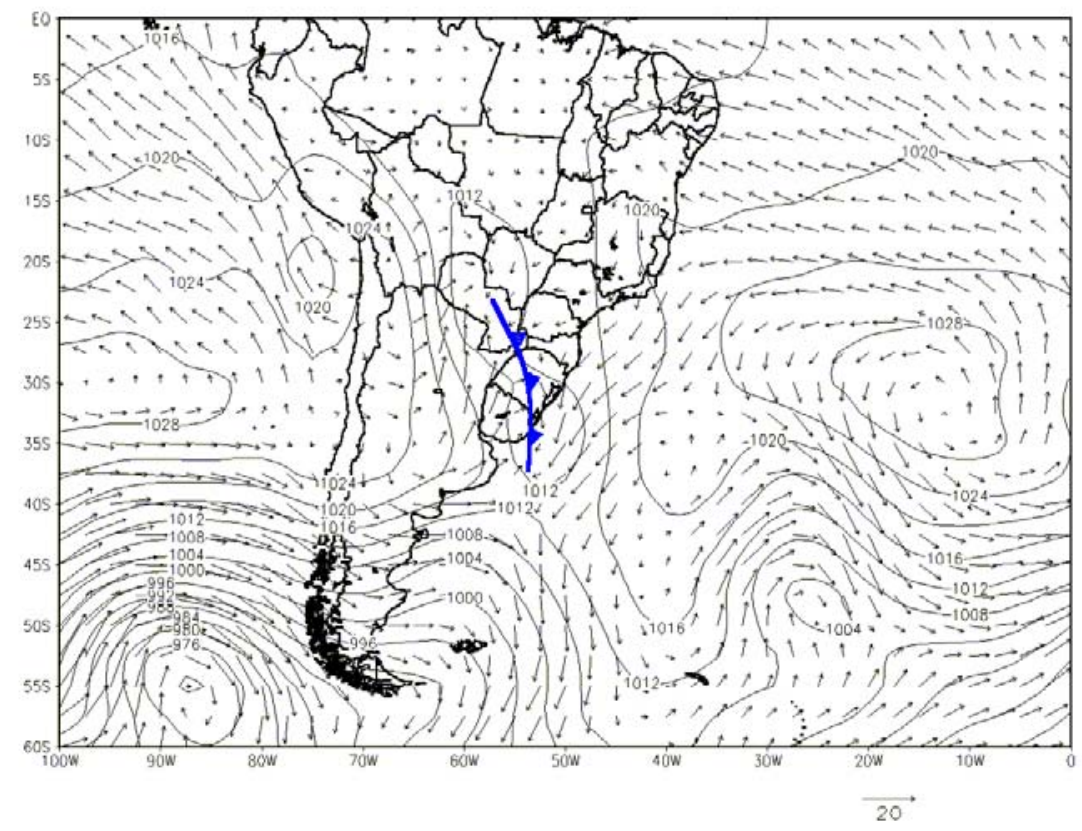

(Figura 2a)

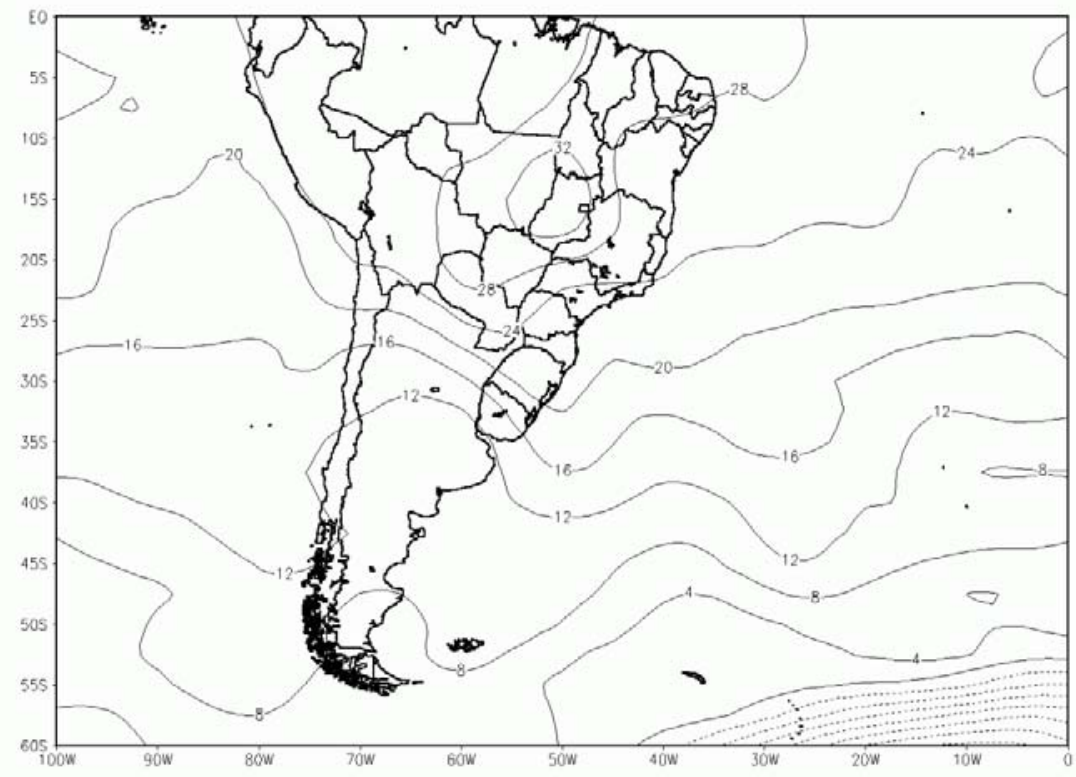

(Figura 2b)

ral argentino. No verão, Justi da Silva \& Silva Dias (2000) identificaram um máximo da frequência frontal no sul da Argentina, em torno de $45^{\circ} \mathrm{S}$, numa região considerada altamente frontogenética (Satyamurty \& Mattos, 1989) e ciclogenética, ou seja, favorável à formação e intensificação de ciclones (Gan \& Rao, 1991) nesta época do ano. Em meses de inverno, este número máximo de sistemas frontais estende-se para latitudes mais próximas ao Uruguai. Nesta mesma região e também durante 0 inverno, Satya- 


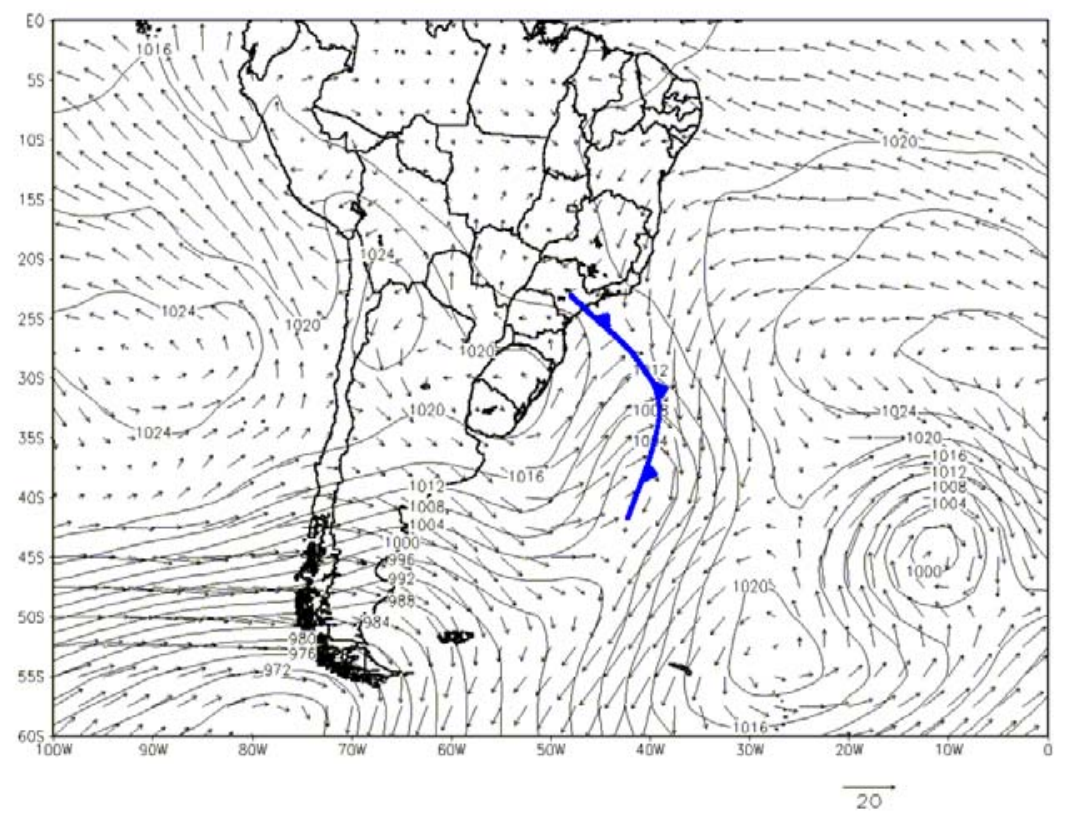

(Figura 2c)

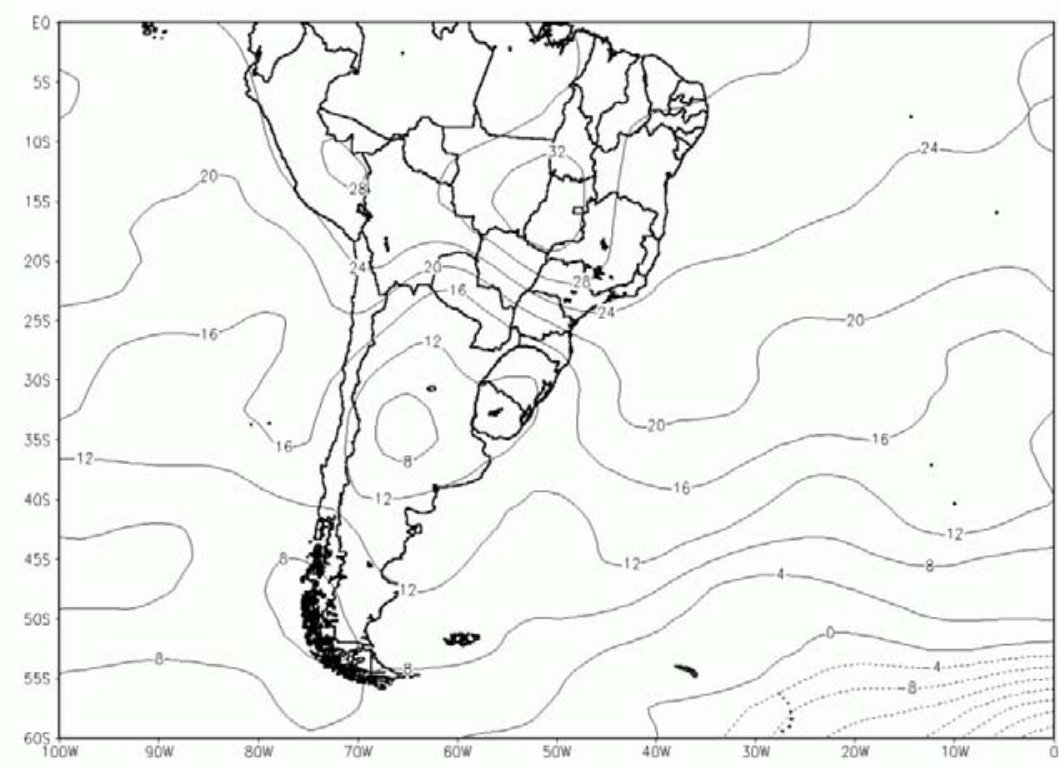

(Figura 2d)

Figura 2 - Campos de pressão ao nível do mar (hPa), vento a 10 metros de altura $(\mathrm{m} / \mathrm{s})$, e temperatura ( ${ }^{\circ} \mathrm{C}$ ) em $1000 \mathrm{hPa}$, no dia 9 (a e b) e dia 10 (c e d) de agosto de 1996, às 1200 UTC, para um caso de frente fria no Sul do Brasil. 0 intervalo de contorno é $4 \mathrm{hPa}$ para pressão, e $4^{\circ} \mathrm{C}$ para temperatura. A localização da frente fria na superfície é mostrada.

Figure 2 - Fields of sea level pressure (hPa), 10-m above ground level wind (m/s), and temperature ( ${ }^{\circ} \mathrm{C}$ ) at $1000 \mathrm{hPa}$, at 1200 UTC of gth August, 1996 (a and b) and 10 th August, 1996 ( $\mathrm{c}$ and d), for one case of the cold front at Southern Brazil. The countour interval is $4 \mathrm{hPa}$ for pressure, and $4^{\circ} \mathrm{C}$, for temperature. The location of the surface cold front is also marked. 
murty \& Mattos (1989) e Gan \& Rao (1991) encontraram, respectivamente, a função frontogenética mais forte e a maior frequência de ciclogênese.

No Sul do Brasil, os estudos de Oliveira (1986), Lemos \& Calbete (1996) e Justi da Silva \& Silva Dias $(2000,2002)$ identificaram uma frequência frontal relativamente maior nos meses de maio a dezembro, diminuindo entre janeiro e abril. Mesmo assim, o maior número de frentes frias, encontrado nos meses de inverno e primavera, não difere muito em relação ao período de verão e outono.

No litoral do Sudeste do Brasil, estes mesmos autores encontraram um número de sistemas frontais relativamente maior em meses de inverno, quando comparado ao período de verão. 0 maior tempo de permanência dos sistemas, no entanto, foi observado nos meses de verão, em associação à atividade da Zona de Convergência do Atlântico Sul (ZCAS) (Satyamurty et al., 1998).

\section{DADOS E METODOLOGIA Dados}

Foram usados neste estudo dados de reanálises do NCEP-NCAR, de pressão ao nível do mar, temperatura do ar em $1000 \mathrm{hPa}$, e vento a 10 metros de altura, no período de janeiro de 1990 a dezembro de 1999, e da região da América do Sul e parte do Oceano Atlântico adjacente, localizada entre as longitudes de $100^{\circ} \mathrm{We}$ $20^{\circ} \mathrm{E}$ e as latitudes de $70^{\circ} \mathrm{S} \mathrm{e} 0^{\circ}$. Estes dados estão disponíveis em grade horizontal de $2.5^{\circ} \times 2.5^{\circ}$, com resolução temporal a cada 6 horas, nos horários das 06, 12, 18 e 00 UTC. Segundo Kalnay et al. (1996), as reanálises do NCEP-NCAR são consideradas uma base de dados meteorológicos das mais completas e consistentes disponíveis hoje. Para a retirada da variação diurna, optou-se por trabalhar com as informações médias diárias, determinadas a partir da média aritmética destes 4 horários. A variabilidade dos campos a ser examinada é dessa forma dominada pelos sistemas meteorológicos e massas de ar que passam sobre a região em estudo.

\section{Metodologia \\ Identificação de frentes frias}

Para identificar as frentes frias que atingiram o litoral catarinense, com o uso de reanálises do NCEP-NCAR, no período de 199099, escolheu-se o ponto de grade localizado na região marítima mais próxima do sul do Estado, em $30^{\circ} \mathrm{S}$ e $47.5^{\circ} \mathrm{W}$ (Fig. 1). A passagem de frentes frias, neste ponto, foi considerada através da verificação dos seguintes critérios, em sequência:

(i) giro do vento de quadrante norte para quadrante sul, o que representa uma inversão no sinal do vento meridional de negativo para positivo;

(ii) permanência do vento sul por pelo menos mais de um dia;

(iii) queda de temperatura no momento do giro do vento, ou até dois dias depois, de pelo menos 0.5 grau Celsius.

Esses critérios foram aplicados objetivamente sobre as reanálises usando um algoritmo numérico, e a adequação tanto desses critérios como do algoritmo foi verificada através da análise visual de uma amostra aleatória de vários casos de passagens frontais. Conforme visto no exemplo dado anteriormente, as frentes frias, em latitudes médias, podem ser identificadas através das variações dos campos de vento e temperatura em superfície. 0 giro do vento caracteriza 0 instante da passagem frontal, enquanto o declínio de temperatura, associado à penetração do anticiclone polar, pode ser simultâneo ao giro do vento ou ocorrer posteriormente.

Para eliminar os casos de frentes frias que resultaram em mudanças pouco significativas nos campos atmostéricos, considerou-se um tempo de permanência do vento sul de pelo menos mais um dia após a passagem frontal.

Na etapa de identificação das frentes frias, foram encontrados alguns casos em que a inversão do vento meridional (de norte para sul) é verificada em associação à formação de cavados ou ciclones no oceano, próximo ao litoral, quando a virada do vento foi acompanhada de queda de pressão e aumento da temperatura, ao contrário do que seria esperado em decorrência de uma passagem frontal. Assim, em sequência à virada e permanência do vento sul, considerou-se também a queda da temperatura.

A variação da temperatura potencial equivalente foi testada, em substituição à variação da temperatura, por tratar-se de um parâmetro conservativo e, portanto, teoricamente mais adequado para a identificação de frentes (Wallace e Hobbs, 1997), mas não houve alterações nos resultados.

Os critérios utilizados no presente trabalho mostraram-se adequados para a identificação de frentes frias na região em estudo, localizada em latitudes médias, e esta metodologia apresenta algumas semelhanças com a metodologia empregada por Kousky (1979), ao identificar passagens frontais no litoral da região Nordeste do Brasil. Neste caso, entretanto, o autor optou pela verificação do contraste de umidade, considerando que o contraste térmico é pouco expressivo na região em estudo, durante passagens frontais. 


\section{Climatologia das frentes frias}

Para estabelecer a climatologia de frentes frias no litoral catarinense identificadas em $30^{\circ} \mathrm{S}$ e $47.5^{\circ} \mathrm{W}$, foram determinadas:

(i) as composições dos campos médios de pressão ao nível do mar e de vento a 10 metros, em 5 dias consecutivos: 0 dia anterior (-1), 0 dia da passagem frontal (0) e 3 dias depois $(+1,+2 \mathrm{e}+3)$;

(ii) as variações do vento meridional a 10 metros de altura e da temperatura em $1000 \mathrm{hPa}$ (variáveis utilizadas na identificação das frentes), no ponto de referência, no período entre 0 dia anterior e até três dias depois da passagem frontal $(-1,0,+1,+2 \mathrm{e}+3)$;

(iii) a frequência de frentes frias $\mathrm{e} 0$ intervalo de dias entre duas passagens frontais consecutivas.

Na definição de campos ou variáveis em períodos sazonais, foram considerados como meses de verão, dezembrojaneiro-fevereiro (DJF); outono, março-abril-maio (MAM); inverno, junho-julho-agosto (JJA); primavera, setembro-outubronovembro (SON).

\section{RESULTADOS E DISCUSSÕES Campos médios em superfície}

A partir da identificação de frentes frias no litoral sul catarinense, foram determinados para as duas estações do ano mais significativas, verão e inverno, os campos médios de pressão ao nível do mar e de vento a 10 metros, em 5 dias consecutivos: 0 dia anterior $(-1), 0$ dia da passagem frontal no ponto de referência (0) e três dias depois $(+1,+2, e+3)$ (Fig. 3). Esses campos médios foram obtidos mediante técnica da composição de dados, sendo que 99 casos de passagens frontais foram considerados para verão, e 100 casos para 0 inverno. A estatística da freqüência de frentes frias no litoral de Santa Catarina é mostrada com mais detalhes mais adiante.

Um dias antes de atingir o litoral catarinense, as frentes frias são observadas no Rio Grande do Sul, tanto em meses de verão como de inverno (Figs. 3a, 3b), mas neste último, o cavado é mais pronunciado, forçando um intenso fluxo de noroeste no litoral sul catarinense. Note-se também que a posição média das frentes frias no inverno é mais setentrional, o que indica um deslocamento mais rápido em direção às latitudes mais baixas.

No dia da passagem frontal em $30^{\circ} \mathrm{S}$ e $47.5^{\circ} \mathrm{W}$, a frente fria já pode ser observada na altura do litoral de São Paulo, em ambas as estações (Figs. 3c, 3d), e um fluxo de sudoeste predomina no litoral Sul do Brasil, forçado na retaguarda do cavado que se intensifica próximo à costa. Uma região de forte gradiente de pressão é observada no litoral do Rio Grande do Sul e sul de Santa Catarina, sendo ainda mais intensa em meses de inverno.

Um dia depois de seu deslocamento por Santa Catarina, a frente fria atinge 0 litoral do Rio de Janeiro. No verão (Fig. 3e), o cavado associado ao sistema frontal enfraquece e avança rapidamente em direção ao Atlântico, seguido do anticiclone móvel, cujo centro pode ser observado no oceano, altura de $35^{\circ} \mathrm{S}$, provocando um fluxo de sudeste no litoral catarinense. No inverno (Fig. 3f), entretanto, o cavado ainda é profundo e afasta-se mais lentamente, mantendo um intenso fluxo de sudeste em sua retaguarda, na região costeira de Santa Catarina.

Dois dias depois, não é possível identificar a frente fria nas composições dos meses de verão (Fig. $3 \mathrm{~g}$ ). Um fluxo de leste passa a predominar no litoral de Santa Catarina, associado à presença do cavado invertido, no litoral da região Sudeste do Brasil. No inverno (Fig. 3h), a frente fria entra em dissipação no oceano e 0 cavado, em latitudes médias, afasta-se mais lentamente da costa. 0 centro do anticiclone móvel pode ser observado no litoral Sul do Brasil, em torno de $30^{\circ} \mathrm{S}$, enfraquecendo os ventos na região.

Depois de três dias da passagem frontal, o padrão climatológico é predominante, em meses de verão (Fig. 3i), com a atuação da alta subtropical do Atlântico Sul ocasionando ventos de nordeste ao longo da costa sul e sudeste do Brasil. No inverno (Fig. 3j), verifica-se 0 anticiclone móvel integrando-se ao anticiclone do Atlântico Sul.

Conforme a Fig. 3, os sistemas frontais avançam até o litoral de São Paulo, em meses de verão, dissipando-se mais rapidamente sobre 0 oceano, dois dias depois de passarem por Santa Catarina. No inverno, entretanto, as frentes frias avançam ao longo do litoral Sudeste do Brasil, chegando a atingir o Rio de Janeiro e Espírito Santo. Nestes Estados, Justi da Silva \& Silva Dias (2000 e 2002) verificaram um relativo aumento da frequência de frentes frias, durante 0 inverno.

Os centros de alta e baixa pressão que acompanham 0 sistema frontal seguem uma trajetória de oeste para leste, em latitudes médias, forçando o giro do vento, no sentido anti-horário, no litoral de Santa Catarina. Mas este fluxo no pré e pós-frontal apresenta características sazonais bem definidas, associado às diferentes trajetórias de deslocamento e intensidade dos ciclones e anticiclones que acompanham as frentes frias.

No verão, com o rápido deslocamento dos sistemas migratórios em latitudes mais ao sul, os fluxos de noroeste ou sudoeste não são persistentes no litoral catarinense, durante a pas- 


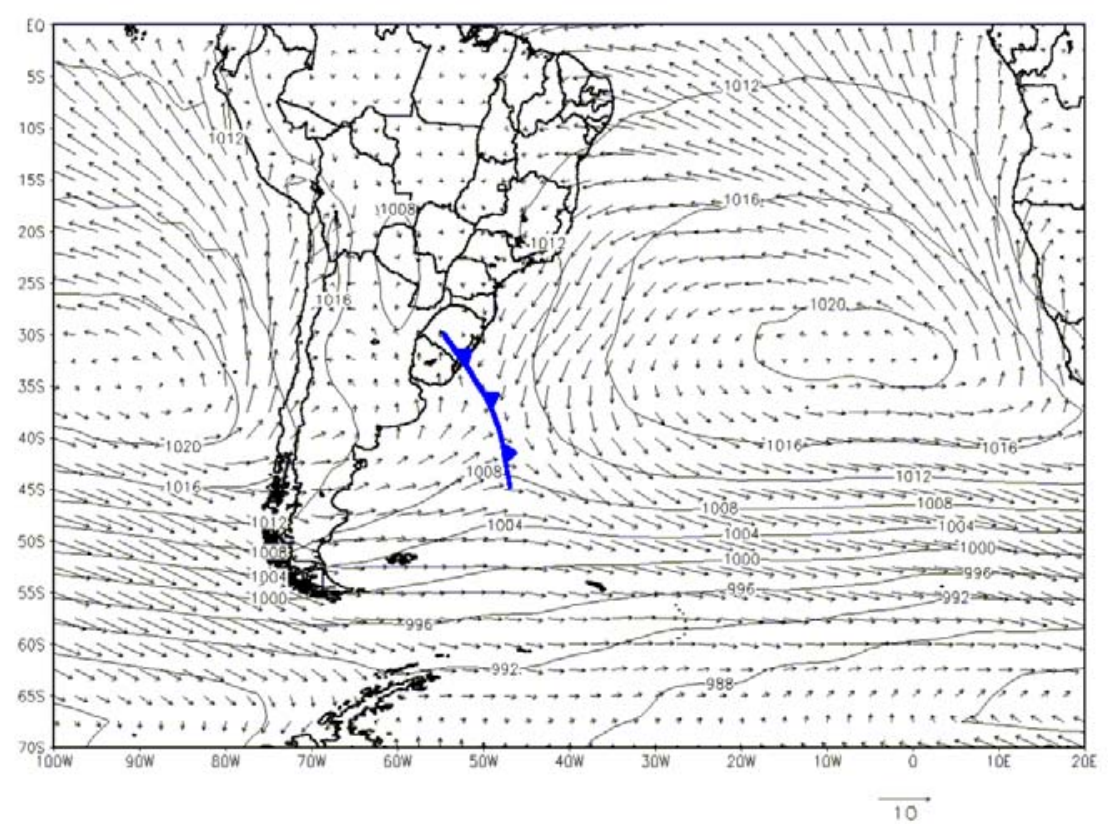

(Figura 3a)

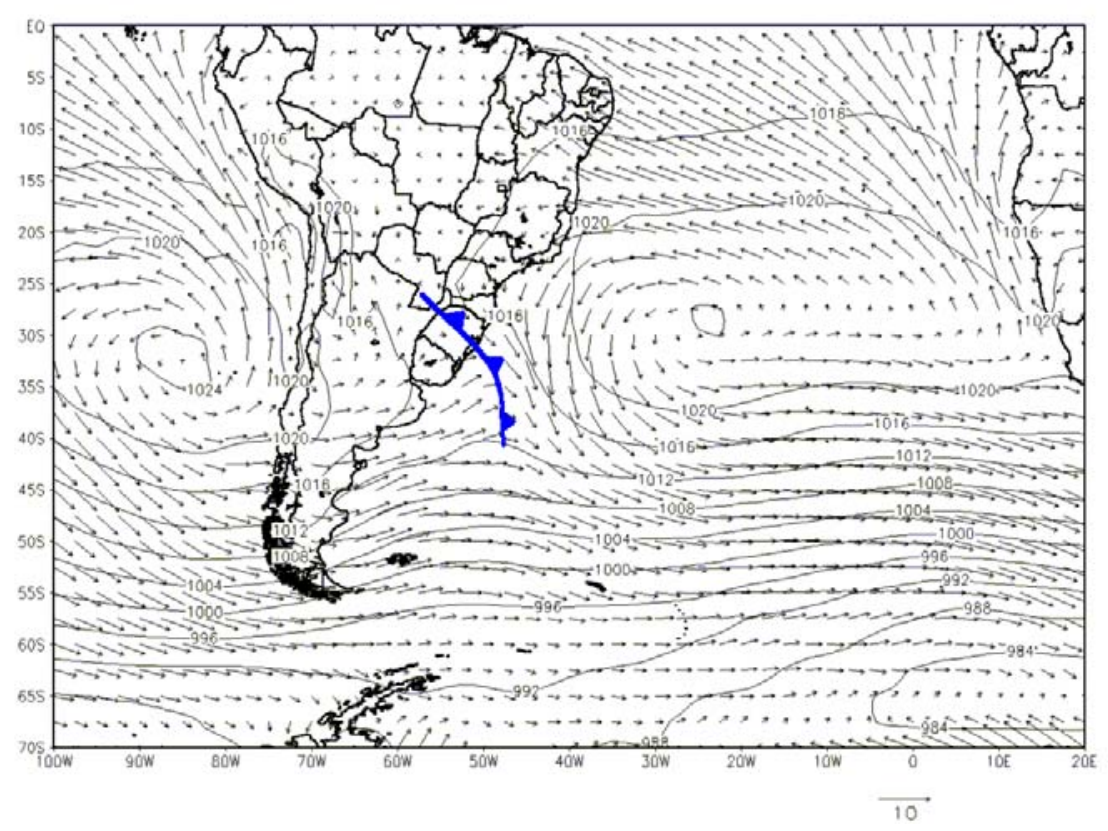

(Figura 3b)

sagem frontal, e não aparecem nos campos médios da Fig. 3.

Em meses de inverno, ao contrário, o cavado aparece bem mais acentuado e desloca-se lentamente em latitudes próximas ao sul do Brasil, o que resulta num intenso fluxo de sudoeste no lito- ral catarinense, em dois dias consecutivos (Figs. 3d, 3f). Gan \& Rao (1991) identificaram a região entre $35^{\circ} \mathrm{S}$ e $30^{\circ} \mathrm{S}$, no litoral sudeste da América do Sul, como preferencial para a intensificação de ciclones (ciclogênese) durante 0 inverno. 


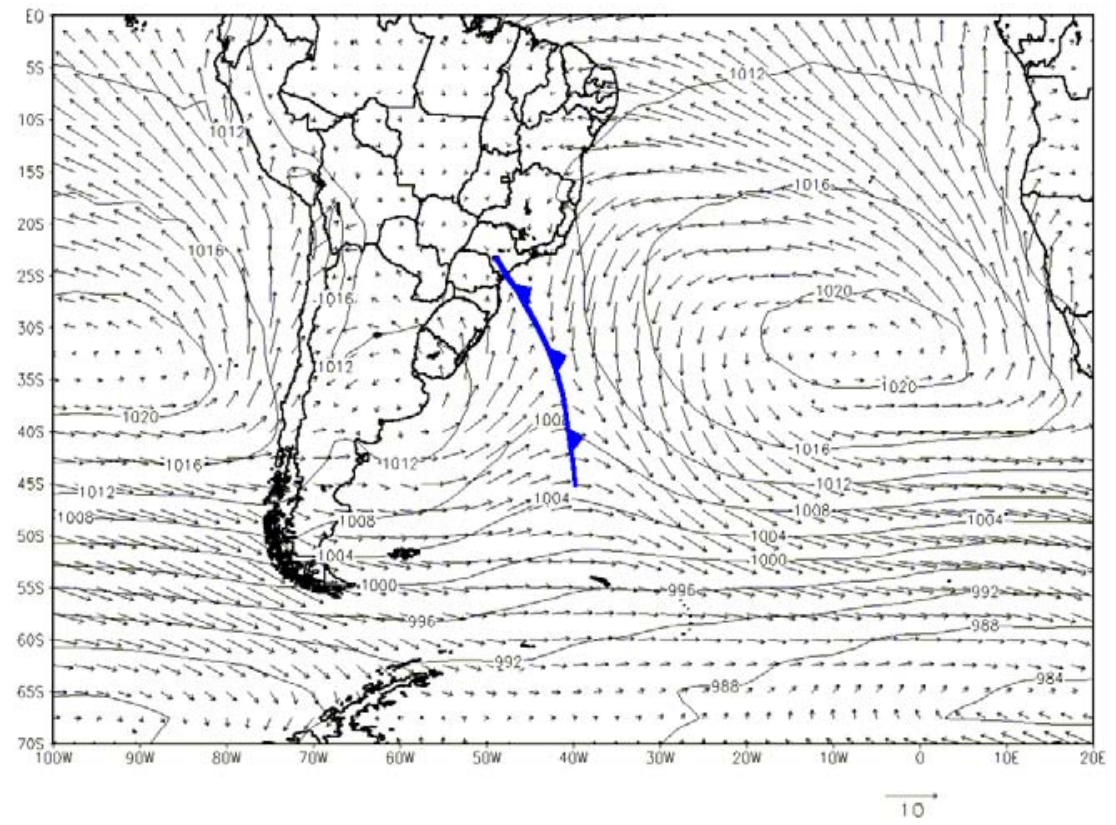

(Figura 3c)

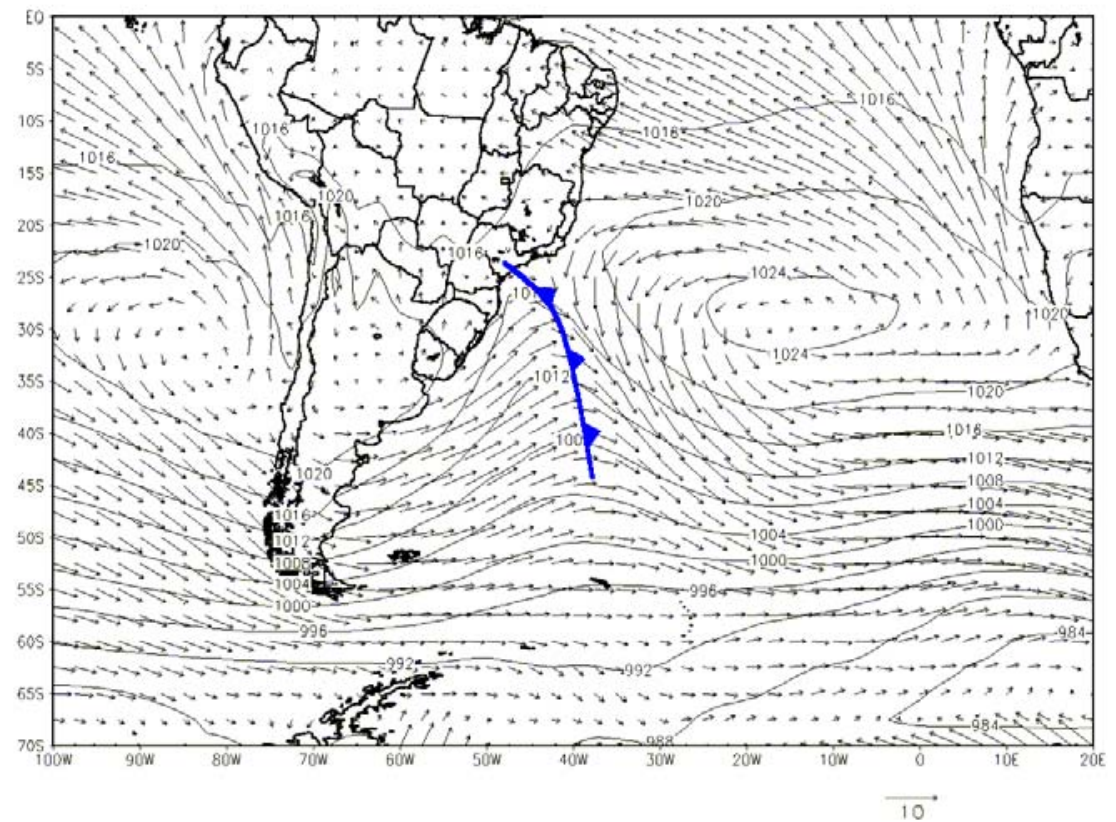

(Figura 3d) 


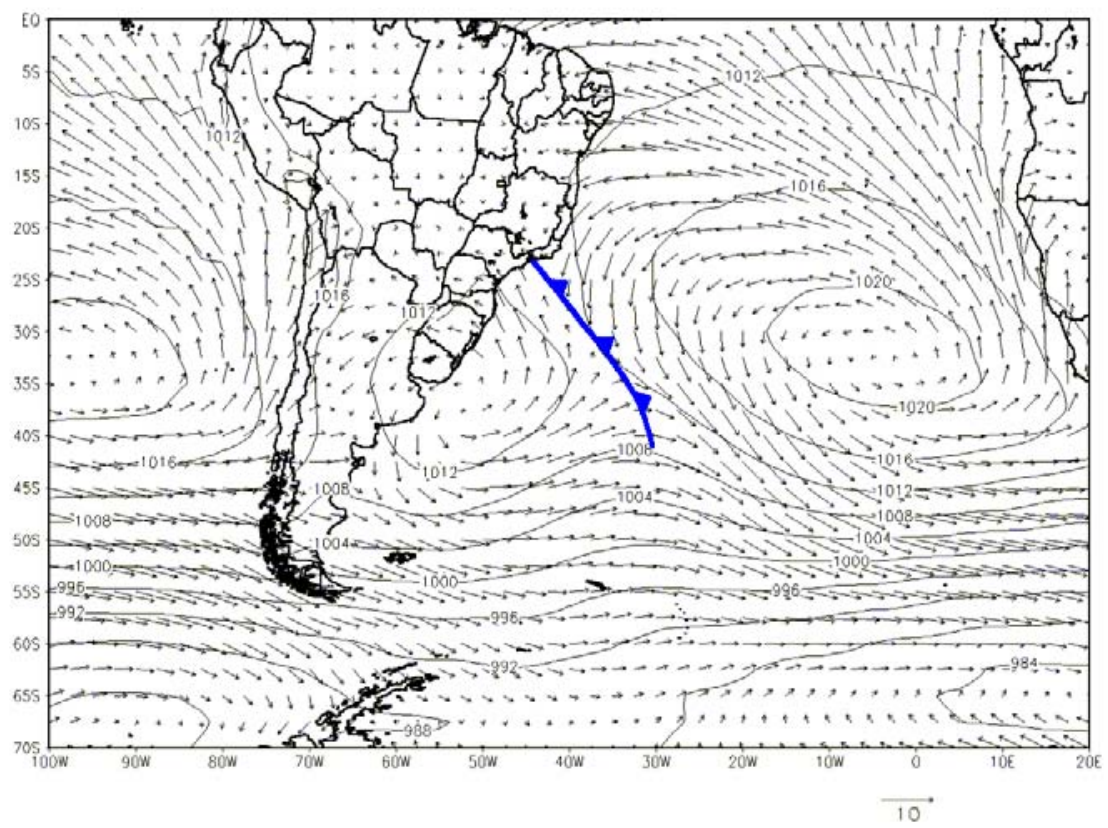

(Figura 3e)

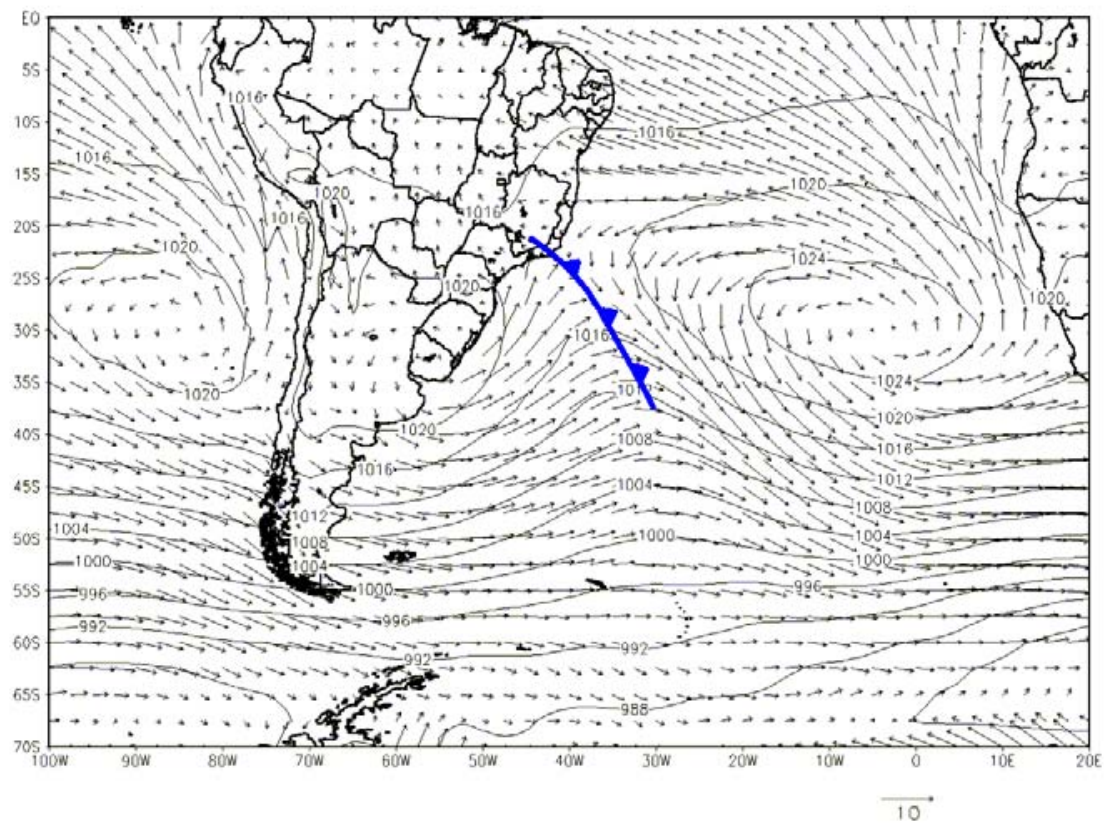

(Figura 3f) 


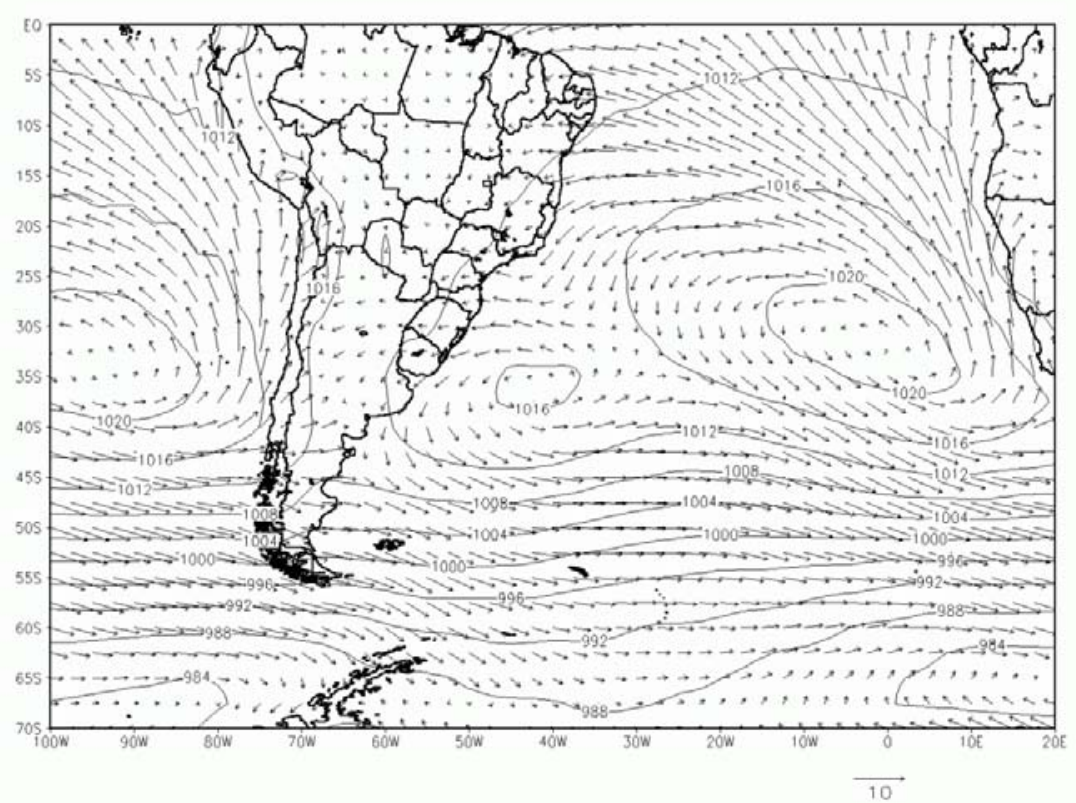

(Figura 3g)

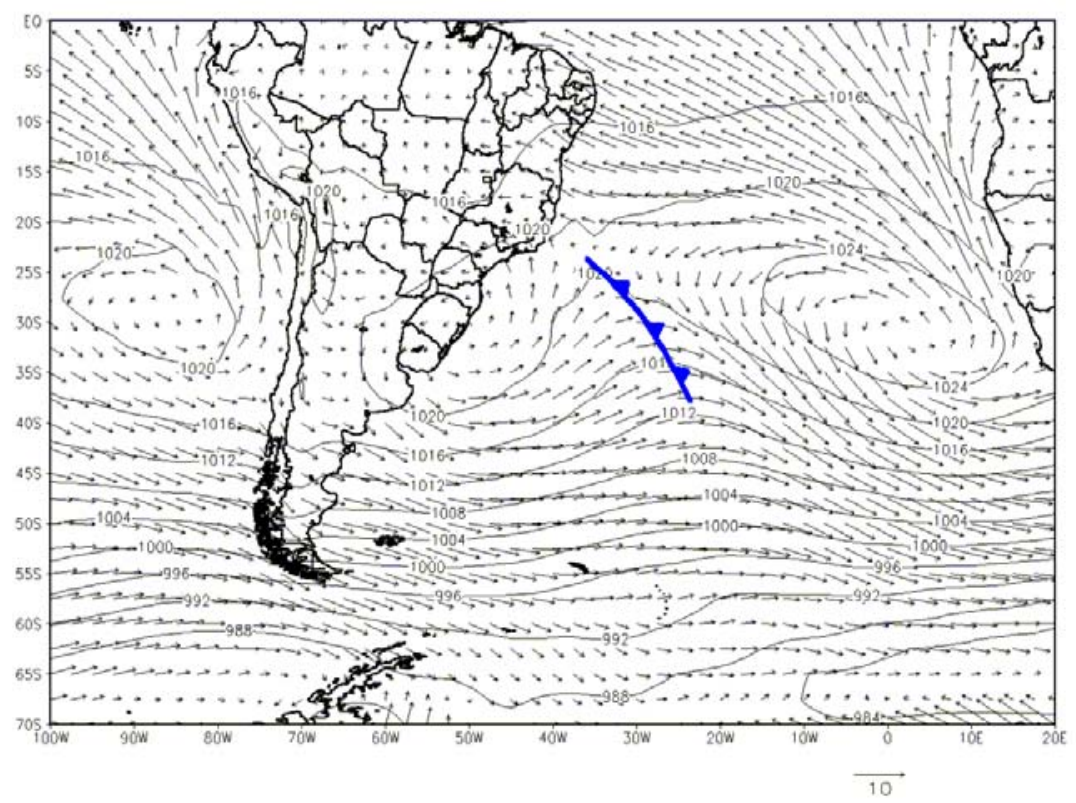

(Figura 3h)

Um fluxo de sudeste e leste é forçado no litoral de Santa Catarina durante o período de verão, no primeiro e segundo dia após a passagem frontal no Estado (Figs. 3e, 3g), em associação ao cavado invertido que se configura no litoral dos Estado do Sudeste do Brasil, quando as frentes atingem esta região. A presença deste cavado parece associada à Zona de Convergência do Atlântico Sul (ZCAS) (Satyamurty et al., 1998), característica da estação de verão.

Ao estudar a variação anual da frequência de ciclones no Atlântico Sul, Sugahara (2000) identificou um número máximo 


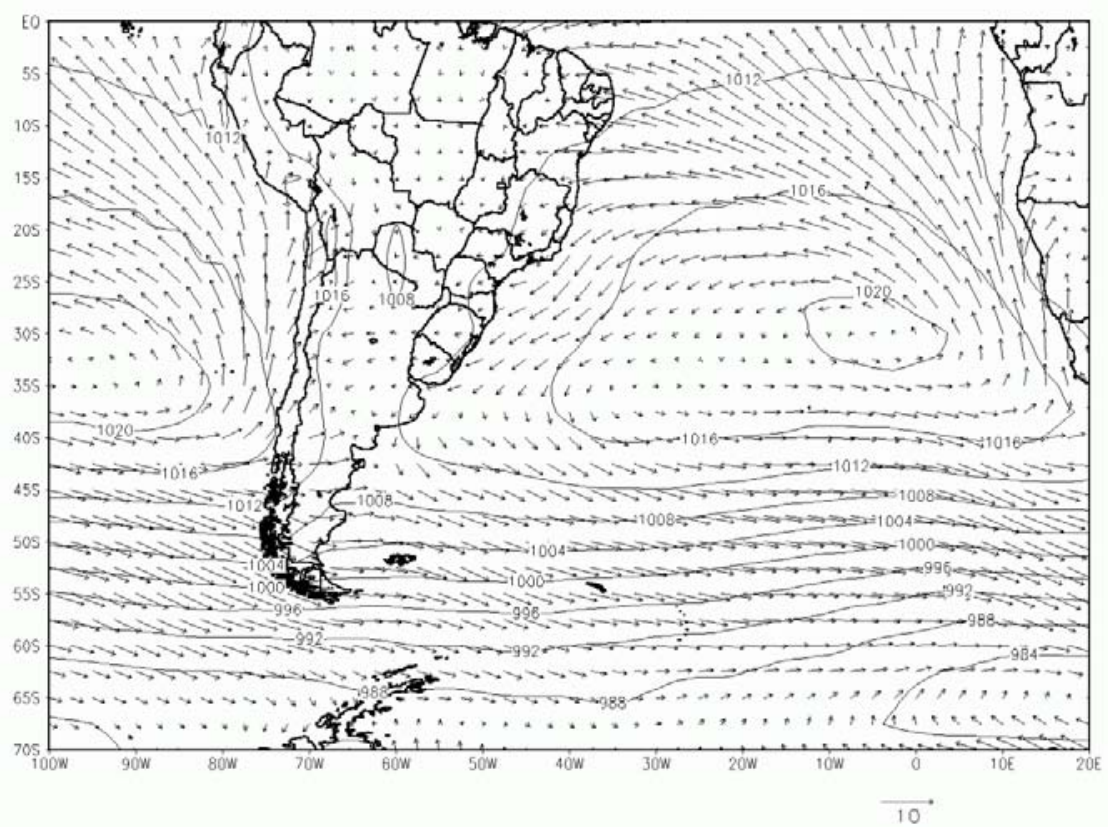

(Figura 3i)

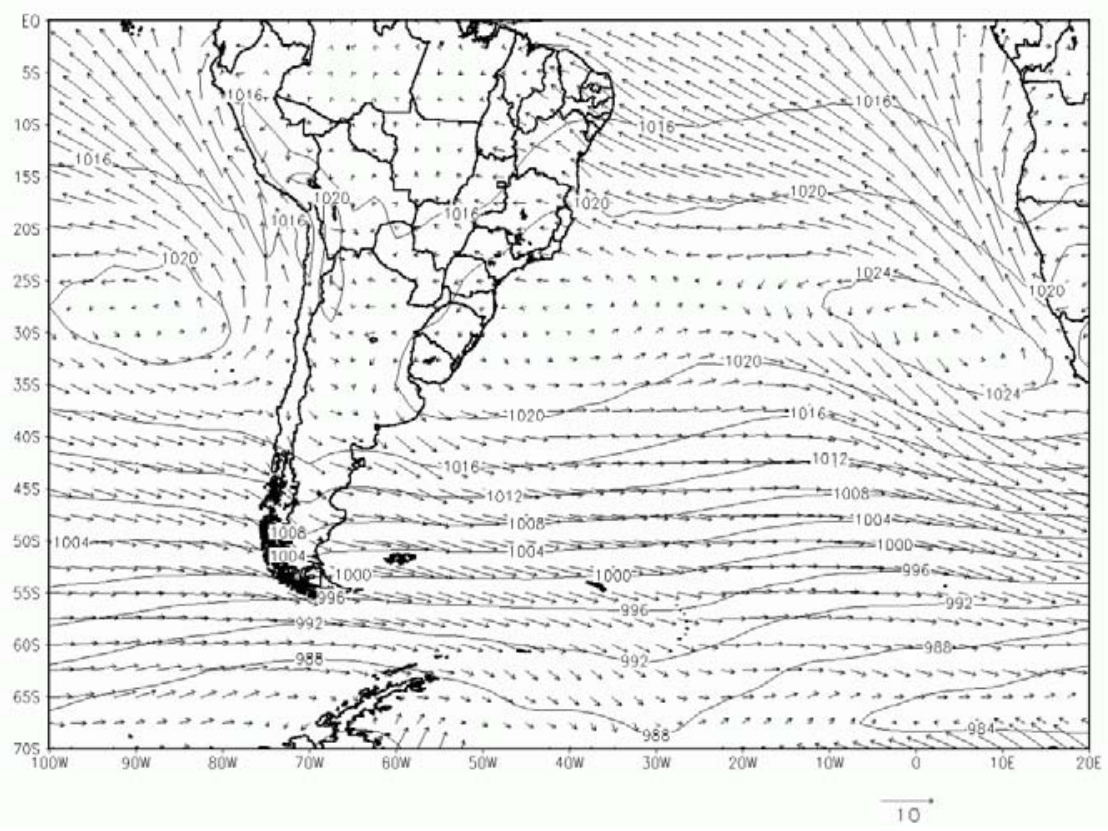

(Figura 3j)

Figura 3 - Campos médios de pressão ao nível do mar (hPa) e de vento a 10 metros de altura ( $\mathrm{m} / \mathrm{s})$, para passagens frontais em $\left(30^{\circ} \mathrm{S}\right.$ e $\left.47.5^{\circ} \mathrm{W}\right)$, em meses de verão (a,c,e,g,i) e de inverno (b,d,f,h,j). 0 intervalo de contorno é 4hPa; a localização da frente fria na superfície é mostrada.

Figure 3 - Average fields of sea level pressure (hPa) and 10-m above ground level wind $(\mathrm{m} / \mathrm{s})$, for cold fronts passages at $\left(30^{\circ} \mathrm{S}\right.$ e $\left.47.5^{\circ} \mathrm{W}\right)$, in summer months $(a, c, e, g, i)$ and winter months $(b, d, f, h, j)$. The contour interval is $4 h$ Pa and the location of surface cold front is also marked. 
local de sistemas na costa dos Estados de São Paulo, Paraná e Santa Catarina, especialmente nos meses de outubro a abril, sugerindo uma associação da ZCAS com vórtices ciclônicos em baixos níveis.

\section{Variações dos campos médios, no ponto selecionado}

Nas Tabelas 1 e 2, são mostradas as médias sazonais do vento meridional a 10 metros de altura e da temperatura do ar em $1000 \mathrm{hPa}$, verificadas no ponto de identificação das frentes frias, no litoral sul de Santa Catarina, para os 5 dias consecutivos da passagem frontal. No caso do vento meridional (Tab. 1), sinal negativo (-) corresponde a um fluxo de norte e sinal positivo (+), a um fluxo de sul. Para a temperatura do ar (Tab. 2) foram também determinadas as variações em 24 horas.

Tabela 1 - Média sazonal, para verão (DJF), outono (MAM), inverno (JJA) e primavera (SON) e para o período de 1990 a 1999, do vento meridional a 10 metros da superfície $(\mathrm{m} / \mathrm{s})$, na passagem de frentes frias em $30^{\circ} \mathrm{S}$ e $47.5^{\circ} \mathrm{W}$.

Table 1 - Seasonal mean, for summer (DJF), autumn (MAM), winter (JJA) and spring (SON) for period from 1990 to 1999, of 10-m above ground level meridional wind $(\mathrm{m} / \mathrm{s})$, during cold front passages at $\left(30^{\circ} \mathrm{S}\right.$ e $\left.47.5^{\circ} \mathrm{W}\right)$.

\begin{tabular}{c|c|c|c|c}
\hline Dias & DJF & MAM & JJA & SON \\
\hline$(-1)$ & -3.9 & -4.1 & -4.2 & -4.7 \\
$(0)$ & 3.7 & 3.6 & 4.1 & 4.6 \\
$(+1)$ & 4.3 & 4.5 & 5.1 & 4.3 \\
$(+2)$ & -0.1 & 1.0 & 1.4 & -0.6 \\
\hline
\end{tabular}

Comparadas em um mesmo dia, as médias do vento meridional (Tab. 1) apresentam uma variação sazonal relativamente pequena, sendo ligeiramente mais intensas na primavera (dias -1, 0) e inverno (dias +1 e +2 ). Nas quatro estações, o fluxo de norte, um dias antes da chegada da frente fria, aparece praticamente tão intenso quanto o fluxo de sul, verificado no dia da passagem do sistema e dia seguinte. No segundo dia (+2), os ventos enfraquecem e o fluxo de sul permanece como predominante durante 0 inverno e outono.

0 padrão de variação da temperatura em 24 horas (Tab. 2) é semelhante em todas as épocas do ano. 0 declínio observado no dia da passagem frontal (0) é seguido de um declínio mais acentuado no dia seguinte $(+1)$. Na sequência (+2), a temperatura sofre pouca ou nenhuma alteração, elevando-se no terceiro dia depois da passagem das frentes em Santa Catarina (+3), quando a alta subtropical do Atlântico Sul volta a predominar no litoral sul e sudeste do Brasil, tanto em meses de verão como de inverno (Figs. 3i, 3j). Embora as maiores variações sejam verificadas no período de inverno, seguido dos meses de primavera e outono, é interessante notar que, mesmo no verão o declínio de temperatura é bem caracterizado, em associação à passagem frontal.

\section{Frequência de frentes frias}

Um total de 429 casos de frentes frias foi identificado em $30^{\circ} \mathrm{S}$ e $47.5^{\circ} \mathrm{W}$, em 10 anos de dados (1990-1999) de reanálises do NCEP-NCAR, os quais são apresentados mês a mês na Tabela 3.

As médias mensais de frentes frias que atingem o litoral de Santa Catarina não chegam a apresentar grandes diferenças entre si, mas um número ligeiramente maior de sistemas foi encontrado em setembro, outubro e novembro, ou seja na primavera. Em cada um destes meses encontra-se uma frequência frontal em torno de $10 \%$ do total anual e as maiores médias mensais, de 4 frentes frias. No período de verão, outono e inverno, a média mensal é de 3 a 3,5 frentes frias. Os meses de fevereiro, abril e junho aparecem como os de menor frequência de frentes frias (7\% do total anual), quando em média 3 frentes frias atingem 0 litoral de Santa Catarina. A maior variabilidade da média mensal foi verificada em janeiro, fevereiro, março e junho, enquanto os meses de primavera estão entre os de menor desvio (Tab. 3).

No período da primavera, encontra-se um número médio de 12,6 frentes frias, o que corresponde a $30 \%$ dos sistemas identificados no litoral catarinense durante 0 ano. Nas demais estações, a média é de 10 frentes frias no trimestre (25\% do total anual).

Assim como neste estudo, Oliveira (1986), Lemos \& Calbete (1996) e Justi da Silva \& Silva Dias (2002) também verificaram uma atuação das frentes frias, no litoral de Santa Catarina, em todas as épocas do ano, com um ligeiro aumento do número durante a primavera. Estes autores encontraram um número ligeiramente menor de frentes frias nos meses de verão e outono, em média.

Estes estudos apresentaram, no entanto, diferenças em relação ao número médio de sistemas observados em cada mês. Na Fig. 4, são apresentados os resultados obtidos por Oliveira (1986) e Lemos \& Calbete (1996), que analisaram dados nos períodos de 1975-1984 (10 anos) e 1987-1995 (9 anos), respectivamente, em conjunto com os resultados do presente trabalho (1990-1999). As diferenças no número de frentes frias, obtido por cada autor, podem ser explicadas pelas diferentes metodologias empregadas e períodos de amostragem.

As frequências de frentes frias encontradas neste estudo ficaram próximas àquelas encontradas em Lemos \& Calbete (1996), que identificaram uma média mensal de 3 a 4,5 sistemas atingindo 0 litoral de Santa Catarina (Fig. 4). Os autores identificaram as frentes frias através de cartas sinóticas das 12 e 00 UTC e de ima- 
Tabela 2 - Média sazonal, para verão (DJF), outono (MAM), inverno (JJA) e primavera (SON) e para o período de 1990 a 1999 , da temperatura em $1000 \mathrm{hPa}\left({ }^{\circ} \mathrm{C}\right)$ e variação em 24 horas, na passagem de frentes frias em $30^{\circ} \mathrm{S}$ e $47.5^{\circ} \mathrm{W}$.

Table 2 - Seasonal mean, for summer (DJF), autumn (MAM), winter (JJA) and spring (SON) for the period from 1990 to 1999 , of air temperature at $1000 \mathrm{hPa}\left({ }^{\circ} \mathrm{C}\right)$ and 24 -h variation, during cold front passages at $\left(30^{\circ} \mathrm{S}\right.$ e $\left.47.5^{\circ} \mathrm{W}\right)$.

\begin{tabular}{c|c|c|c|c|c|c|c|c}
\hline \multicolumn{4}{c|}{ Temperatura média sazonal } & \multicolumn{4}{c}{ Variação em 24 horas } \\
\hline Dias & DJF & MAM & JJA & SON & DJF & MAM & JJA & SON \\
\hline$(-1)$ & 22,9 & 21,7 & 17,9 & 19,4 & & & & \\
$(0)$ & 22,4 & 20,9 & 16,5 & 18,5 & $-0,5$ & $-0,8$ & $-1,4$ & $-0,9$ \\
$(+1)$ & 20,5 & 18,7 & 13,8 & 16,2 & $-1,9$ & $-2,2$ & $-2,7$ & $-2,3$ \\
$(+2)$ & 20,7 & 18,6 & 13,8 & 16,4 & 0,2 & $-0,1$ & 0 & 0,2 \\
$(+3)$ & 21,4 & 19,4 & 15 & 17,4 & 0,7 & 0,8 & 1,2 & 1 \\
\hline
\end{tabular}

Tabela 3 - Número mensal de passagens frontais, em 30 S e 47,5 W, no período de 1990 a 1999.

Table 3 - Monthly number of cold front passages, at $30^{\circ} \mathrm{S}$ and $47,5^{\circ} \mathrm{W}$, for the period from 1990 to 1999.

\begin{tabular}{c|c|c|c|c|c|c|c|c|c|c|c|c|c}
\hline Ano & Jan & Fev & Mar & Abr & Mai & Jun & Jul & Ago & Set & Out & Nov & Dez & Total \\
\hline 1990 & 3 & 2 & 4 & 2 & 2 & 5 & 3 & 4 & 4 & 3 & 4 & 4 & 40 \\
\hline 1991 & 4 & 5 & 3 & 4 & 1 & 4 & 3 & 4 & 4 & 5 & 4 & 2 & 43 \\
\hline 1992 & 3 & 2 & 1 & 4 & 3 & 1 & 5 & 4 & 4 & 5 & 5 & 3 & 40 \\
\hline 1993 & 3 & 3 & 5 & 2 & 4 & 5 & 3 & 4 & 3 & 3 & 3 & 3 & 41 \\
\hline 1994 & 5 & 2 & 4 & 5 & 3 & 3 & 2 & 4 & 3 & 5 & 5 & 4 & 45 \\
\hline 1995 & 6 & 3 & 3 & 2 & 4 & 4 & 4 & 2 & 5 & 5 & 4 & 5 & 47 \\
\hline 1996 & 3 & 2 & 4 & 3 & 5 & 2 & 4 & 4 & 4 & 5 & 5 & 4 & 45 \\
\hline 1997 & 2 & 3 & 3 & 2 & 3 & 3 & 4 & 4 & 5 & 4 & 4 & 3 & 40 \\
\hline 1998 & 2 & 6 & 5 & 3 & 6 & 2 & 2 & 3 & 6 & 4 & 5 & 3 & 47 \\
\hline 1999 & 4 & 2 & 5 & 4 & 5 & 1 & 5 & 2 & 3 & 4 & 3 & 3 & 41 \\
\hline Média & 3.5 & 3.0 & 3.7 & 3.1 & 3.6 & 3.0 & 3.5 & 3.5 & 4.1 & 4.3 & 4.3 & 3.4 & 42.9 \\
\hline Desvio & 1.3 & 1.4 & 1.3 & 1.1 & 1.5 & 1.5 & 1.1 & 0.8 & 1.0 & 0.8 & 0.8 & 0.8 & \\
\hline
\end{tabular}

gens do satélite GOES-8, canal infravermelho, no período de 9 anos, entre 1987 e 1995, considerando como sistemas atuantes no litoral catarinense os mesmos que penetraram no extremo sul do Brasil.

Oliveira (1986), por outro lado, encontrou uma frequência maior de frentes frias (Fig. 4), a média mensal variando de 6,5 a 7,5 entre maio e dezembro, e de 5 a 6 entre janeiro e abril. Este autor selecionou casos de frentes frias em quatro bandas de latitude (entre $45^{\circ} \mathrm{S}$ e $20^{\circ} \mathrm{S}$ ), ao longo do litoral, através da análise subjetiva de imagens de satélite geoestacionário GOES-EAST, entre 1975 e 1984, considerando somente as frentes frias que apresentaram nebulosidade sobre 0 continente, uma vez que 0 objetivo do estudo era a associação entre penetrações frontais na América do Sul e a atividade convectiva na Amazônia. Neste caso, foram considerados como sistemas atuantes até uma latitude de $25^{\circ} \mathrm{S}$ os mesmos que ultrapassaram a latitude de $35^{\circ} \mathrm{S}$.

Justi da Silva \& Silva Dias (2002) identificaram a frequência sazonal de penetrações frontais na região entre $10^{\circ} \mathrm{S}$ e $60^{\circ} \mathrm{S}$ e $90^{\circ} \mathrm{W}$ e $30^{\circ} \mathrm{W}$, com base em 19 anos (1981-1999) de dados de reanálise do NCEP-NCAR das 12 e 00 UTC, obtendo uma média de 13 sistemas frontais no litoral sul catarinense, durante o verão, 15 nas demais estações do ano. As frentes frias foram selecionadas a partir da virada do vento meridional de norte para sul, em cada ponto de grade, enquanto no presente estudo encontrou um menor número de sistemas (Tab. 3), considerando-se, além da virada, uma permanência do vento sul e o declínio de temperatura. 


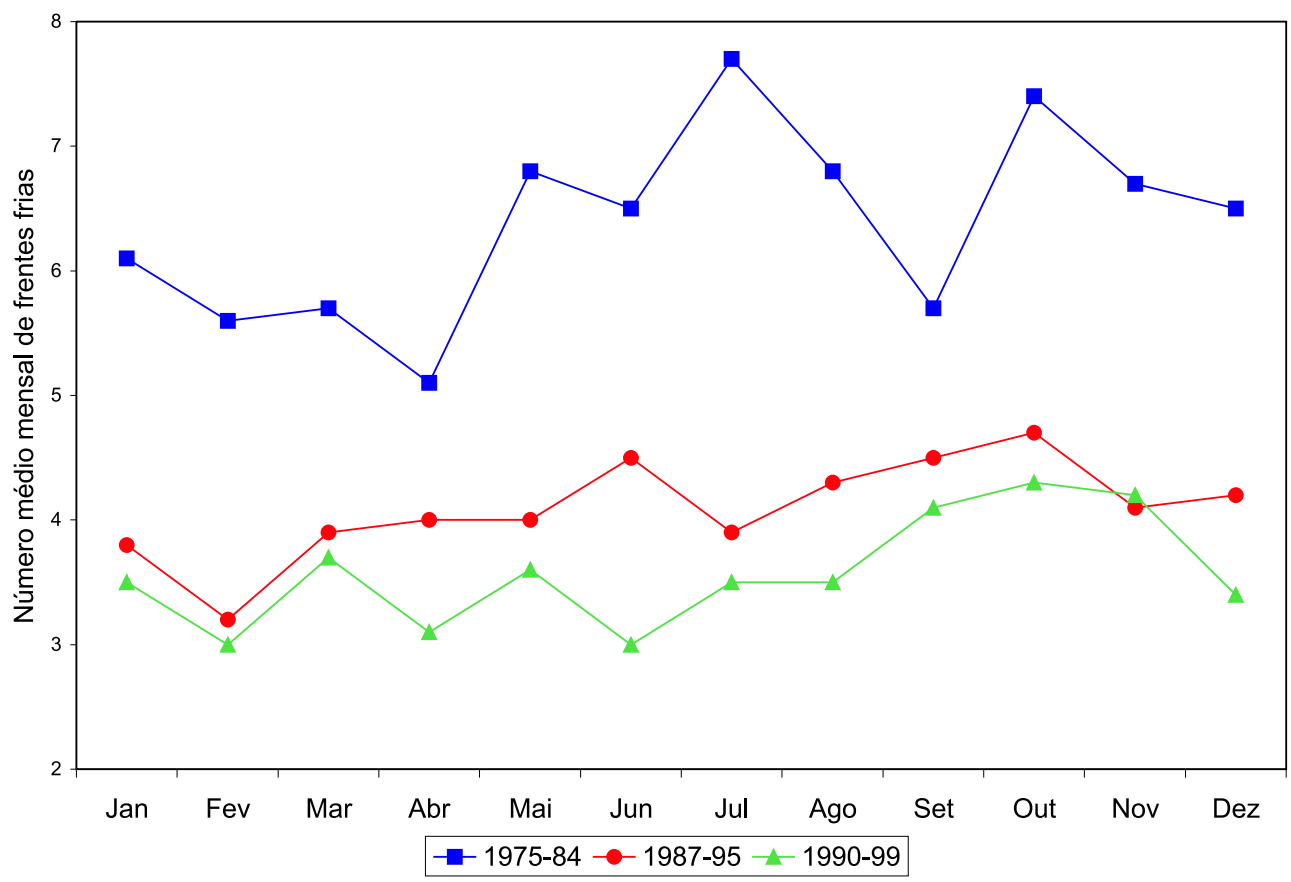

Figura 4 - Número médio mensal de frentes frias em diferentes estudos no litoral de Santa Catarina.

Figure 4 - Monthly average of the number of cold fronts in different studies at coast of Santa Catarina.

\section{Estatística de intervalos entre duas passagens frontais consecutivas}

Dentro do período analisado (1990-1999) e considerando o ponto de identificação de frentes frias, determinou-se o número de dias de intervalo entre duas passagens frontais consecutivas, obtendose a distribuição de frequência apresentada na Fig. 5.

0 intervalo médio entre duas passagens frontais no litoral de Santa Catarina, determinado a partir da média aritmética, ficou em 8 dias. Com base em cartas sinóticas e dados de estações costeiras, Stech \& Lorenzzetti (1992) identificaram um intervalo médio de 7 dias entre passagens frontais no litoral sul-sudeste brasileiro.

Na Fig. 5, nota-se que mais de 50\% dos sistemas frontais atingem Santa Catarina em um intervalo de 3 a 8 dias. Períodos prolongados sem ocorrência de passagens frontais na região são bem menos frequentes e intervalos superiores a 14 dias envolvem menos de $20 \%$ dos casos analisados. 0 intervalo mínimo encontrado, entre passagens consecutivas, foi de 3 dias e o máximo, de 25 a 32 dias.

Vale lembrar que estes intervalos de frequência frontal são válidos para sistemas com permanência do vento sul por pelo menos mais um dia após a passagem frontal, conforme critério adotado para a identificação das frentes.

\section{CONCLUSÕES}

A climatologia de frentes frias, definida neste estudo com base em 10 anos de dados de reanálise do NCEP-NCAR, de 1990 a 1999, mostra a trajetória típica de deslocamento das frentes frias, de sudoeste para nordeste, durante 3 dias em média, ao longo do litoral sul e sudeste do Brasil.

Verificou-se uma frequência média mensal de 3 a 4 frentes frias atingindo Santa Catarina em todos os meses do ano, com um número ligeiramente maior desses sistemas durante a primavera. Estes resultados ficaram bem próximos aos obtidos em estudos anteriores baseados em cartas de superfície, indicando os dados de reanálises do NCEP como adequados para a identificação de sistemas frontais na região em estudo.

No critério de identificação de frentes frias, considerou-se a virada do vento e o declínio de temperatura, variações características em latitudes médias. 0 padrão de variação da temperatura mostrou-se bem definido e semelhante em todas as épocas do ano, mesmo para passagens frontais em meses de verão, com um declínio mais acentuado no dia seguinte à passagem frontal. Este critério, no entanto, pode não ser adequado para outras regiões do litoral brasileiro.

0 intervalo médio entre duas passagens frontais consecutivas é de 8 dias, porém mais de $50 \%$ das frentes frias atingem 


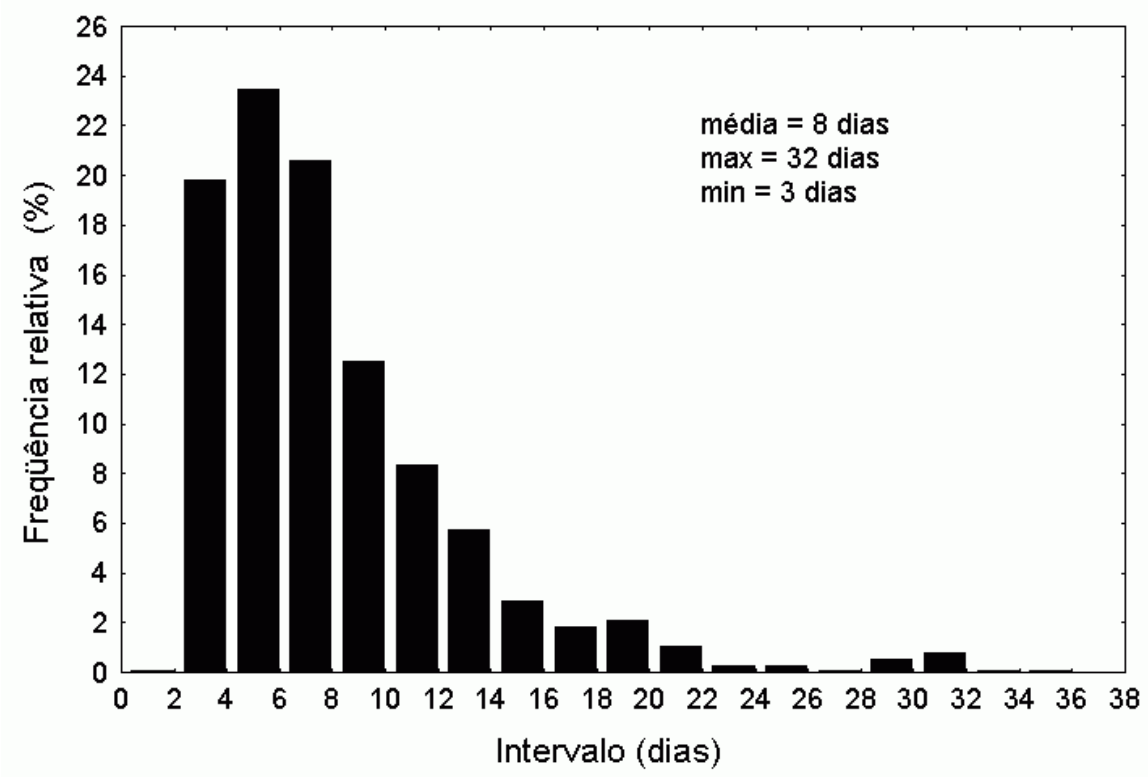

Figura 5 - Distribuição de freqüência do número de dias de intervalo entre passagens de frentes frias em $30^{\circ} \mathrm{S}$ e $47.5^{\circ} \mathrm{W}$. Figure $\mathbf{5}$ - Frequency distribution of number of days of interval among cold front passages at $30^{\circ} \mathrm{Se} 47.5^{\circ} \mathrm{W}$.

0 litoral catarinense em um intervalo entre 3 e 8 dias. Embora com uma frequência muito pequena, intervalos bem maiores, de 25 a 32 dias, foram encontrados em meses de verão, outono e inverno, provavelmente associados à ocorrência de bloqueios atmosféricos. Os meses de primavera, além de uma frequência frontal relativamente maior, também apresentam uma menor variabilidade do número de sistemas, quando comparados aos demais meses do ano.

A frequência média mensal de frentes frias não varia muito durante 0 ano, no litoral de Santa Catarina, mas pode-se identificar uma variação sazonal no campo de vento pós-frontal. No inverno, um intenso fluxo de sudoeste é verificado nos 2 dias seguintes à passagem frontal, em associação a ciclones que se intensificam no oceano, em latitudes próximas à costa sul do Brasil (Gan \& Rao, 1991). No verão, os ciclones deslocam-se em latitudes mais altas e os ventos de sudeste são típicos de uma condição pós-frontal no litoral catarinense, associados à atuação de sistemas de baixa pressão (ciclones e cavados) que se configuram na altura do litoral Sudeste do Brasil, após a passagem frontal nesta região.

\section{AGRADECIMENTOS}

M.L.G. Rodrigues agradece aos Drs. Hamilton da Epagri, Elói Mello da UFSC, Rosmeri Porfírio da Rocha da USP, e ao MSc. Ruy Prudêncio de Sá da UFSC. Os autores agrade- cem ao NOAA-CIRES Climate Diagnostic Center por ter disponibilizado as reanálises do NCEP através do web site http://www.cdc.noaa.gov/. Este trabalho é parte da dissertação de mestrado da M.L.G. Rodrigues.

\section{REFERÊNCIAS}

AMBRIZZI T \& PEZZA AB. 1999. Cold Waves and the Propagation of Extratropical Cyclones and Anticyclones in South America: a SynopticClimatological Overview. Revista Geofísica, 51: 45-67.

CAMARGO R \& HARARI J. 1994. Modelagem Numérica de Ressacas na Plataforma Sudeste do Brasil a partir de Cartas Sinóticas de Pressão Atmosférica na Superfície. Boletim do Instituto Oceanográfico, 42: 19-34.

CASTRO B \& LEE T. 1995. Wind-forced Sea Level Variability on the Southeast Brasilian Shelf. Journal of Geophysical Research, 100: 16045-16056.

CAVALCANTI IF \& KOUSKY VE. 1996. Configuração de Anomalias Associadas à Propagação de Sistemas Sinóticos sobre a América do Sul. Anais do IX Congresso Brasileiro de Meteorologia, Campos do Jordão, 1331-1332.

GAN MA \& RAO VB. 1991. Surface Cyclogenesis over South America. Monthly Weather Review, 119: 1293-1302.

INNOCENTINI V \& CAETANO NETO E. 1996. A case study of the 9 August 1998 South Atlantic storm : Numerical simulations of the wave activity. Weather and Forecasting, 11: 78-88. 
JUSTI DA SILVA MGA \& SILVA DIAS MAF. 2000. A Estatística dos transientes na América do Sul. Anais do XI Congresso Brasileiro de Meteorologia, Rio de Janeiro.

JUSTI DA SILVA MGA \& SILVA DIAS MAF. 2002. A frequência de fenômenos meteorológicos na América do Sul: uma climatologia. Anais do XII Congresso Brasileiro de Meteorologia, Foz do Iguaçu.

KALNAY E et al. 1996. The NCEP/NCAR 40-Year Reanalysis Project. Bulletin of the American Meteorological Society, 77: 437-472.

KOUSKY VE. 1979. Frontal Influences on Northeast Brasil. Monthly Weather Review, 107: 1140-1153.

LEMOS CF \& CALBETE NO. 1996. Sistemas Frontais que atuaram no Brasil de 1987 a 1995. Climanálise Especial, Edição comemorativa de 10 anos. MCT/INPE-CPTEC.

OLIVEIRA AS. 1986. Interações entre Sistemas Frontais na América do Sul e Convecção na Amazônia. INPE-4008-TDL/239.

ROCHA RP, SUGAHARA S \& SILVEIRA RB. 2004. Sea waves generated by extratropical cyclones in the South Atlantic Ocean: hindcast and validation against altimeter data. Weather and Forecasting, 19: 398-410.

SATYAMURTY P \& MATTOS LF. 1989. Climatological Lower Tropospheric Frontogeneis in the Midlatitudes Due to Horizontal Deformation and
Divergence. Monthly Weather Review, 117: 1355-1364.

SATYAMURTY P, MATTOS LF, NOBRE CA \& SILVA DIAS PL. 1998. Tropics - South America. In : Meteorology of the Southern Hemisphere, Ed. Kauly, D. J. and Vincent, D. G., Meteorological Monograph. American Meteorological Society, Boston, 119-139.

STECH JL \& LORENZZETTI JA. 1992. The response of the South Brazi Bight to the Passage of Wintertime Cold Fronts. Journal of Geophysical Research, 97, C6, 9507-9520.

SUGAHARA S. 2000. Variação Anual da Frequência de Ciclones no Atlântico Sul. XI Congresso Brasileiro de Meteorologia, II Encontro Brasileiro de Interação 0ceano-Atmosfera, Rio de Janeiro, 1: 2607-2611.

TALJAARD JJ. 1967. Development, Distribution and Movement of Cyclones and Anticyclones in the Southern Hemisphere During the IGY. Journal of Applied Meteorology, 6: 973-987.

TRUCCOLO EC \& FRANCO D. 2000. Characterization and Prediction of the Meteorological Tides at São Francisco do Sul, SC. Anais do XI Congresso Brasileiro de Meteorologia, Rio de Janeiro, 2752-2757.

WALLACE JM \& HOBBS PV. 1977. Atmospheric Science: An Introductory Survey. Academic Press, Inc, London, 467 pp.

\section{NOTAS SOBRE OS AUTORES}

Maria Laura Guimarães Rodrigues. Mestre em Engenharia Ambiental pela Universidade Federal de Santa Catarina, com graduação em meteorologia pela Universidade Federal de Pelotas. Atuando como meteorologista desde 1987, na UNESP/IPMet-SP e Epagri/Ciram-SC, onde atualmente exerce a Coordenação do Setor de Meteorologia. Experiência nas áreas de previsão de tempo e clima - efetuando palestras e divulgação na mídia (artigos para jornais, apresentação em rádios e TVs) - e estudos climáticos para impactos ambientais.

Davide Franco. Concluiu o doutorado em Scienze Chimiche - Università Degli Studi Di Venezia em 1993. Publicou 19 artigos em periódicos especializados, 59 trabalhos em anais de eventos e 10 capítulos de livros. Recebeu o premio Seymour Cray Itália 1990. Atua na área de Oceanografia, com ênfase em Oceanografia Física. Nos últimos dez anos ocupou-se das forçantes meteorológicas e dos seus efeitos na hidrodinâmica costeira e estuarina de Santa Catarina. Tem interesse na caracterização do regime de ondas na costa, a previsão da componente meteorológica da maré e a circulação residual em baias.

Shigetoshi Sugahara. Pesquisador no Instituto de Pesquisas Meteorológicas, da Universidade Estadual Paulista (Unesp), Campus de Bauru, e docente do curso de pós-gradução em educação para a ciência na Faculdade de Ciências da Unesp de Bauru. Graduado em Física pela Universidade Estadual de Campinas. Mestrado em Meteorologia pelo INPE/SJC, e Doutorado em Meteorologia pela USP. Assuntos de interesse: Climatologia, Métodos estatísticos de dados atmosféricos, controle de qualidade de dados meteorológicos, e previsão estatística de tempo. 